\title{
STUDY OF ASSOCIATION OF DIABETIC MACULOPATHY WITH HYPERLIPIDEMIA
}

\author{
Sivaramareddy Kolli ${ }^{1}$, Ananda Reddy Endreddy², Viswas Reddy ${ }^{3}$ \\ ${ }^{1}$ Associate Professor, Department of Ophthalmology, Katuri Medical College \& Hospital, Guntur. \\ ${ }^{2}$ Assistant Professor, Department of Psychiatry, Katuri Medical College \& Hospital, Guntur. \\ ${ }^{3}$ Post Graduate Student, Department of Ophthalmology, Katuri Medical College \& Hospital, Guntur.
}

\section{ABSTRACT}

\section{BACKGROUND}

Diabetic maculopathy is the most common microvascular complication in diabetes, which can produce severe visual loss. Apart from diabetes, a number of systemic factor like hyperlipidemia has an important role in occurrence and progression of Diabetic Macular Edema. Thus control of these factors along with control of blood sugars can prevent or reverse the maculopathy and thereby restore the vision of diabetic patients.

\section{OBJECTIVES}

To study the association of diabetic maculopathy with Hyperlipidemia to highlight the effect of this factor on onset and/or progression of diabetic maculopathy.

\section{MATERIALS AND METHODS}

A cross-sectional comparative study was carried out in 100 diabetic patient with retinopathy more than 18 years attending Department of Ophthalmology. For all patients visual acuity, slit lamp examination, intraocular pressure, fundus examination was conducted. Patients were divided into 2 groups (Group1 - Retinopathy with maculopathy and Group 2 - Retinopathy without maculopathy). A detailed history of duration of diabetes, type of treatment, hyperlipidemia were taken from the patient. The significance of the hyperlipidemia was compared in both the groups involved in the study.

\section{RESULTS}

In the present study of 100 patients diagnosed with diabetic retinopathy, majority were males (54\% in study group and $58 \%$ in control group) by age 51-60 years. In the study group, majority (76\%) patients had duration of DM>10 years, whereas in control group majority of patients (70\%) had duration 5-10 years. The mean value of PPBS, HbA1C were significantly higher in study group than in control group. In this study among serum lipids, serum cholesterol, serum triglycerides, VLDL and LDL levels were significantly higher in study group compared to control group.

\section{CONCLUSION}

Diabetic maculopathy was significantly associated with hyperlipidemia. Thus early detection of this risk factor and their control prevent the development and progression of maculopathy and thereby prevent the significant visual loss in diabetic patient.

\section{KEYWORDS}

Albuminuria, Diabetic Maculopathy, Glycosylated Haemoglobin, Lipid profile.

HOW TO CITE THIS ARTICLE: Sivaramareddy Kolli, Ananda Reddy Endreddy, Viswas Reddy. "Study of Association of Diabetic Maculopathy with Hyperlipidemia." Journal of Evolution of Medical and Dental Sciences 2015; Vol. 4, Issue 100, December 14; Page: 16506-16509, DOI: 10.14260/jemds/2015/2454

\section{INTRODUCTION}

Diabetic maculopathy is the most common microvascular complication in diabetes, which can produce severe visual loss.[1] Diabetic maculopathy is a form of diabetic retinopathy, in which visual loss occur due to macular edema. It predominantly occur in non-insulin dependent diabetics. ${ }^{[2]}$ Diabetic maculopathy can occur at any level of retinopathy and alter the structure of macula, significantly affecting its function. ${ }^{[3]}$ Treatment of established retinopathy can reduce the risk of visual loss by $60 \% .^{[4]}$ Disturbance in lipid metabolism have been implicated in the pathogenesis of diabetic retinopathy. Elevated serum lipid levels are associated with an increased risk of retinal hard exudates in persons with diabetic retinopathy.[5,6]

Financial or Other, Competing Interest: None.

Submission 21-11-2015, Peer Review 23-11-2015,

Acceptance 07-12-2015, Published 11-12-2015.

Corresponding Author:

Dr. Sivaramareddy Kolli,

Associate Professor,

Department of Ophthalmology,

Katuri Medical College \& Hospital,

Guntur-522019.

E-mail:dr.sivram_kolli@yahoo.com

DOI:10.14260/jemds/2015/2454
Retinal hard exudates usually accompanies diabetic macular edema, increasing amounts of exudates appear to be independently associated with an increased risk of visual impairment.[7] The elevated lipid levels are also associated with endothelial dysfunction, which appears to play an important role in the pathogenesis of diabetic maculopathy, particularly in relation to the breakdown of blood-retinal barrier. ${ }^{[8,9]}$ In India the prevalence of diabetic retinopathy in general population is $3.5 \%$ and the prevalence of diabetic retinopathy in the population with diabetes mellitus is $18.0 \% .{ }^{[10]}$ In a population-based study in South India, diabetic retinopathy was detected in $1.78 \%$ of the diabetic patients screened.[11,12] According to the World Diabetes Atlas, India is projected to have around 51 million people with diabetes. There is a growing concern for Asia being the region for diabetic epidemic.[13,14]

Epidemiological Study of Diabetic retinopathy found a statistically association between elevated serum cholesterol and LDL and the severity of retinal hard exudation in patients with diabetic retinopathy. The present study is to highlight systemic factors like hyperlipidemia, which can affect onset and/or progression of diabetic maculopathy and the association between them.[15,16]

Once diabetic maculopathy occurs, there is no satisfactory treatment and the prognosis is very poor, so it is 
better to prevent its development.[17] Hence, there is need to find out the risk factor associated with clinically significant macular edema and to control the same, reduce the incidence of Diabetic maculopathy in future.[18]

\section{MATERIALS AND METHODS}

A cross-sectional study was conducted in 100 diabetic patients with retinopathy attending Department of Ophthalmology (Katuri Medical College and Hospital) in the period of September 2012 to April 2014 to assess the association between hyperlipidemia with diabetic maculopathy.

\section{Method of Collection of Data}

Study Area: Hospital Based

Design of Study: Cross-Sectional, Comparative Study.

Sampling Technique: 100 patients of Diabetic retinopathy were included for this study by simple random sampling method. All subjects underwent detailed ocular examination, fundoscopy and other required investigations to assess the association between diabetic maculopathy with hyperlipidemia.

Sample Size: A total of 100 Type 2 diabetic patients, which included 50 patients having both retinopathy and maculopathy (Study Group); 50 patients having retinopathy without maculopathy (Control Group).

\section{Inclusion Criteria}

a) Diabetic Retinopathy with or without maculopathy patients of both sexes.

b) Diabetic retinopathy patient aged more than 18 years.

\section{Exclusion Criteria}

a) Patients who have had an episode of thyroid or chronic inflammatory syndrome, Alcoholism or Malnutrition.

b) Patients on diuretics, B-Blocker, Hypolipidemic agents or any other drug or hormone know to influence lipid or lipid protein metabolism, were not included.

c) Patients having familial hyperlipidemia.

d) Non-diabetic cases of maculopathy (E.g. Toxic Maculopathy, Retinal Vein Occlusion, Infective Cause, Retinal Dystrophy, ARMD, Trauma).

e) Patients who have undergone any intraocular surgery, intraocular laser treatment or intraocular injections in the past 3 months.

Data Analysis: Data collected entered on excel spread sheet after coding and further processed using SPSS Version 17.0 (Statistical package for social sciences). The data analysis was done by computing proportions, mean of standard deviation. Appropriate test of significance was used based on type of data. A P value $<0.05$ was considered significant.

\section{Procedure}

An informed written consent was obtained in every case. A detailed ocular history and medical history was taken. A detailed general physical examination was performed. An elaborate biomicroscopic examination of the anterior segment was performed. Visual acuity was recorded for both distance and near and best corrected visual acuity was recorded. IOP was recorded using Applanation tonometer.

Pupils were dilated with topical medication of $1 \%$ tropicamide and 5\% phenylephrine drops, the latter being omitted in hypertensives. Detailed fundoscopy was done by direct ophthalmoscopy, indirect ophthalmoscopy and slit lamp biomicroscope using 90D and 70D Volk lens.

After fundus examination, only patients having retinopathy in at least one eye were selected for further study and subsequently divided into 2 groups (Study groupRetinopathy with maculopathy and control group-
Retinopathy without maculopathy). Informed consent was taken from the concerned patients. Fundus picture of the patients were taken with DRS and fundus camera. The Diabetic retinopathy was graded according to Early Treatment Diabetic Retinopathy Study (ETDRS) classification.

A detailed history of duration and type of treatment of diabetes, the mean value of the three consecutive blood pressure readings was assessed. Following blood investigation (FBS, PPBS, Glycosylated $\mathrm{Hb}$, Serum lipid profile, Urine albumin, RFT) of the concerned patients were done. HbA1c determination is based on the turbidimetric inhibition immunoassay. Fundus fluorescein angiography was done in all patients to decide on the treatment plan.

\section{RESULTS}

A comparative two group cross-sectional clinical study with 50 patients in each group was undertaken to analyse the influence of systemic risk factors on the development of diabetic maculopathy in type II diabetic patient. The data was analysed using various statistical test like descriptive and inferential statistics, mean \pm SD (Min-Max), student ' $t$ ' test (Two tailed independent) and Chi-square or Fisher Exact Test.

\begin{tabular}{|c|c|c|c|c|}
\hline \multirow{2}{*}{ Age in Years } & \multicolumn{2}{|c|}{$\begin{array}{c}\text { Study Group } \\
\text { (50 PATIENT) }\end{array}$} & \multicolumn{2}{c|}{$\begin{array}{c}\text { Control Group } \\
\text { (50 PATIENTS) }\end{array}$} \\
\cline { 2 - 5 } & N0 & $\mathbf{\%}$ & N0 & $\mathbf{\%}$ \\
\hline $31-40$ & 4 & 8 & 6 & 12 \\
\hline $41-50$ & 8 & 16 & 12 & 24 \\
\hline $51-60$ & 20 & 40 & 21 & 42 \\
\hline $61-70$ & 12 & 24 & 7 & 14 \\
\hline $71-80$ & 6 & 12 & 4 & 8 \\
\hline TOTAL & $\mathbf{5 0}$ & $\mathbf{1 0 0}$ & $\mathbf{5 0}$ & $\mathbf{1 0 0}$ \\
\hline
\end{tabular}

Samples were age matched with $\mathrm{P}=0.573$.

Table 1 shows the age distribution of patients in this study. Majority of patients included in this study were in the age group 51-60 years (40\%). The mean age of the patients in the study group (With CSME) was $57.02 \pm 9.75$ and in control group mean age was $56.42 \pm 9.25$. There was no significant difference in age distribution among the two groups $(\mathrm{P}=0.573)$.

\begin{tabular}{|c|c|c|c|c|}
\hline \multirow{2}{*}{ GENDER } & \multicolumn{2}{|c|}{ Study Group } & \multicolumn{2}{c|}{ Control Group } \\
\cline { 2 - 5 } & NO & $\mathbf{\%}$ & NO & \% \\
\hline MALE & 27 & 54 & 29 & 58 \\
\hline FEMALE & 23 & 46 & 21 & 42 \\
\hline TOTAL & $\mathbf{5 0}$ & $\mathbf{1 0 0}$ & $\mathbf{5 0}$ & $\mathbf{1 0 0}$ \\
\hline \multicolumn{2}{|c|}{ Table 2: Gender distribution of patients studied } \\
\hline
\end{tabular}

Samples were sex matched with $\mathrm{P}=0.266$

Table 2 shows the sex distribution of the patients in this study. In the study group, out of 50 patients $27(54 \%)$ were males and $23(46 \%)$ were females. In the control group $29(58 \%)$ were males and $21(42 \%)$ were females. There was no significant difference in the gender distribution among the two groups $(\mathrm{P}=0.266)$.

\begin{tabular}{|c|c|c|c|c|}
\hline \multirow{2}{*}{$\begin{array}{c}\text { Duration } \\
\text { of DM }\end{array}$} & \multicolumn{2}{|c|}{$\begin{array}{c}\text { Study } \\
\text { Group }\end{array}$} & \multicolumn{2}{c|}{$\begin{array}{c}\text { Control } \\
\text { Group }\end{array}$} \\
\cline { 2 - 5 } & No & $\%$ & No & $\%$ \\
\hline 5-10 yrs. & 12 & 24 & 35 & 70 \\
\hline $11-15$ yrs. & 19 & 38 & 10 & 20 \\
\hline $16-20$ yrs. & 14 & 28 & 3 & 6 \\
\hline$>20$ yrs. & 5 & 10 & 2 & 4 \\
\hline Table 3: Distribution of patient as per duration of DM \\
\hline
\end{tabular}

Duration of Diabetics was significantly more in study group with $\mathrm{P}=0.002^{* *}$ 
Table 3 shows the distribution of patients in this study according to the duration of DM. In study group $24 \%$ had duration $5-10$ years, $38 \%$ in between $11-15$ years, $28 \%$ in between $16-20$ years and $10 \%>20$ years. In control group, majority of patients had duration $5-10$ years $(70 \%), 20 \%$ in between $11-15$ years, $6 \%$ in between $16-20$ years and $4 \%$ $>20$ years. This shows that the duration of diabetes was more in study group compared to control group $(\mathrm{P}=0.002)$ and statistically significant.

\begin{tabular}{|c|c|c|c|}
\hline $\begin{array}{c}\text { Lipid } \\
\text { Parameter }\end{array}$ & $\begin{array}{c}\text { Study } \\
\text { Group }\end{array}$ & $\begin{array}{c}\text { Control } \\
\text { Group }\end{array}$ & P value \\
\hline Cholesterol & $212.72 \pm 58.48$ & $175.52 \pm 40.89$ & $<0.001$ \\
\hline Triglyceride & $197.5 \pm 51.43$ & $151.08 \pm 41.08$ & $<0.001$ \\
\hline HDL & $39.8 \pm 10.95$ & $31.52 \pm 12.75$ & 0.063 \\
\hline LDL & $140.8 \pm 45.51$ & $112.54 \pm 30.50$ & $<0.001$ \\
\hline VLDL & $34.72 \pm 8.41$ & $30.8 \pm 7.5$ & 0.017 \\
\hline \multicolumn{4}{|c|}{ Table 4: Comparison of Lipid } \\
Parameters in two groups studied \\
\hline \multicolumn{5}{c}{} \\
\hline
\end{tabular}

\begin{tabular}{|c|c|c|c|c|c|}
\hline \multirow[t]{2}{*}{ CHOLESTEROL } & \multicolumn{2}{|c|}{$\begin{array}{l}\text { STUDY } \\
\text { GROUP } \\
(n=50)\end{array}$} & \multicolumn{2}{|c|}{$\begin{array}{c}\text { CONTROL } \\
\text { GROUP } \\
(n=50)\end{array}$} & $\begin{array}{c}P \\
\text { value }\end{array}$ \\
\hline & No & $\%$ & No & $\%$ & \multirow{4}{*}{$\begin{array}{c}<0.00 \\
1\end{array}$} \\
\hline$<200$ & 21 & 42 & 34 & 68 & \\
\hline $200-240$ & 15 & 30 & 14 & 28 & \\
\hline$>240$ & 14 & 28 & 2 & 4 & \\
\hline & $D i$ & 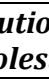 & 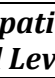 & & \\
\hline
\end{tabular}

In study group out of 50 patients $14(28 \%)$ had high cholesterol, whereas in control group only 2 patients $(4 \%)$ had high cholesterol with $\mathrm{P}<0.001$. Serum cholesterol levels were significantly high in study group. Cholesterol had shown a significant relation with maculopathy.

\begin{tabular}{|c|c|c|c|c|c|}
\hline \multirow{2}{*}{ TGL } & \multicolumn{2}{|c|}{$\begin{array}{c}\text { Study } \\
\text { Group } \\
\text { (n=50) }\end{array}$} & \multicolumn{2}{|c|}{$\begin{array}{c}\text { Control } \\
\text { Group } \\
\text { (n=50) }\end{array}$} & \multirow{2}{*}{ P value } \\
\cline { 2 - 5 } & NO & $\%$ & NO & $\%$ & \\
\hline$<150$ & 9 & 18 & 19 & 38 & \multirow{2}{*}{$<0.001$} \\
\hline $150-200$ & 14 & 28 & 24 & 48 & \\
\hline $200-500$ & 27 & 54 & 7 & 14 & \\
\hline$>500$ & 0 & 0 & 0 & 0 & \\
\hline \multicolumn{2}{|c|}{ Table 6: Distribution of patients as per the TGL level } \\
\hline
\end{tabular}

In study group out of 50 patients $27(54 \%)$ had high triglycerides, whereas in control group only 7 patients (14\%) had high triglycerides with $\mathrm{P}<0.001$. TGL had shown a significant relation with maculopathy.

\begin{tabular}{|c|c|c|c|c|c|}
\hline \multirow{2}{*}{ LDL } & Study Group & \multicolumn{2}{c|}{ Control Group } & \multirow{2}{*}{ P value } \\
\cline { 2 - 5 } & NO & $\%$ & NO & $\%$ & \\
\hline$<100$ & 12 & 24 & 20 & 40 & \\
\hline $100-130$ & 15 & 30 & 16 & 32 & \multirow{2}{*}{$<0.001$} \\
\hline $130-160$ & 7 & 14 & 7 & 14 & \\
\hline $160-190$ & 11 & 22 & 6 & 12 & \\
\hline$>190$ & 5 & 10 & 1 & 2 & \\
\hline \multicolumn{6}{|c|}{ Table 7: Distribution of patients } \\
as per the LDL level \\
\hline
\end{tabular}

In study group, out of 50 patients $16(32 \%)$ had high serum LDL and 7 patients (14\%) had high in control group and $\mathrm{P}<0.001$. Serum LDL levels were significantly high in study group. LDL had shown a significant relation with maculopathy.

\begin{tabular}{|c|c|c|c|c|c|}
\hline \multirow{2}{*}{ VLDL } & \multicolumn{2}{|c|}{$\begin{array}{c}\text { Study Group } \\
\text { (n=50) }\end{array}$} & \multicolumn{2}{c|}{$\begin{array}{c}\text { Control Group } \\
\text { (n=50) }\end{array}$} & \multirow{2}{*}{$\begin{array}{c}\text { P } \\
\text { value }\end{array}$} \\
\cline { 2 - 5 } & NO & $\%$ & NO & $\%$ & \\
\hline$<30$ & 15 & 30 & 24 & 48 & \multirow{2}{*}{0.017} \\
\hline$>=30$ & 35 & 70 & 26 & 52 & $\mathbf{0 . 0 1 7}$ \\
\hline
\end{tabular}

Table 8: Distribution of patients as per the VLDL level

In study group out of 50 patients $35(70 \%)$ had serum VLDL, whereas in control group only 26 patients (52\%) had high serum VLDL with $\mathrm{P}=0.017$. VLDL had shown a significant relation with maculopathy.

\section{DISCUSSION}

Diabetic maculopathy is the most common microvascular complication in diabetes, which can produce severe visual loss. ${ }^{[1]}$ Prevalence of blindness due to diabetes is around 3\%7\% in Southeast Asia according to October 2005 study.[19] Diabetic maculopathy resulting from diabetic retinopathy (DR), is defined as the presence of retinal thickening within one disc diameter or two of the macula.

In our study, serum cholesterol was significantly high in study group $14(28 \%)$ patients compared to the control group $4(8 \%)$ patients $(\mathrm{p}<0.001)$. Serum LDL cholesterol was significantly higher in study group $16(32 \%)$ compared to the control group $7(14 \%)$ with $\mathrm{p}<0.001$, significant higher serum triglycerides value was present in study (54\%) group compared to the control group $(14 \%)(\mathrm{P}<0.001)$, significant higher VLDL cholesterol was present in study group 35(70\%) than control group $26(52 \%)$ with $p=0.017$ and mean of all this parameter significantly higher in study group. In our study serum cholesterol, LDL, VLDL cholesterol, triglycerides shows significant relationship with diabetic maculopathy. But HDL had no significant relationship with Diabetic maculopathy $(\mathrm{p}=0.063)$. Our study was comparable with the following studies.

Early Treatment Diabetic Retinopathy Study (ETDRS) showed that patients with elevated total serum cholesterol levels or serum low-density lipoprotein cholesterol levels at baseline were twice as likely to have diabetic retinal exudation as patients with normal levels. Al-Bdour.[8] found positive relation between diabetic retinopathy and hypercholesterolemia $(\mathrm{p}=0.04)$. Larsson et al.[20] also found significant correlation between higher levels of serum total cholesterol and retinopathy.

The Hoorn Study showed that retinopathy and hard exudates in retinopathy in particular are related to elevated serum total and LDL cholesterol levels, which was comparable to our study. Rebab.[21] in their study demonstrated serum lipids were not associated with DR, in contrast they found strong associations with clinically significant macular edema.

Data from DCCT demonstrated that LDL-C and totalC/HDL-C were associated with increased risk for developing Clinically Significant Macular Edema (CSME). Recent evidence from the Sankara Nethralaya Diabetic Retinopathy Epidemiology and Molecular Genetics Study also demonstrated that patients with Clinically Significant Macular Edema (CSME), but not Diabetic macular edema, had elevated total, non-HDL-C and LDL-C. In the ETDRS, it was reported that higher baseline total and LDL cholesterol levels increase the risk of retinal exudation by two-fold.

In this study serum cholesterol, triglycerides, LDL, VLDL levels were significantly higher in patients with study group. It also showed that the severity of Diabetic retinopathy was more in study group, which was comparable with studies done by Ong Ming et al.(17) 


\section{CONCLUSION}

The increasing number of individuals with diabetes in India suggests that Diabetic retinopathy and diabetic maculopathy will continue to be the major contributors to vision loss and associated functional impairment for years to come. The present study demonstrated significant correlation between diabetic maculopathy with hyperlipidemia. Diabetic maculopathy was more common in the patients having elevated serum cholesterol, triglycerides and LDL and VLDL cholesterol, which was clinically significant. Serum HDL had not shown a correlation with diabetic maculopathy.

\section{REFERENCES}

1. Klein R, Moss SE. The Wisconsin epidemiological study of diabetic retinopathy when age at diagnosis is 30 or more yr. 1984, 102,527.

2. Rahul A, Joshi MM, et al. The Prevalence of Diabetic retinopathy and Correlation with Risk Factors: prospective study. IIPCBS 2013;3(3):716-719.

3. Asensio-Sanchez VM, Gomez-Ramirez, et al. Clinically Significant Diabetic Macular Edema: Systemic Risk Factors. Arch Sos Esp Oftalmol 2008;83:173-176.

4. Malone JI, Morrison AD, Pavan PR, Cuthbertson DD. Diabetic Control and Complications Trial: Prevalence and significance of retinopathy in subjects with type 1 diabetes of less than 5 years duration screened for the diabetes control and complications trial. Diabetes Care 2009;124:522-6.

5. Gupta A, Gupta V, Thapar S, Bhansali A. Lipid-lowering drug atorvastatin as an adjunct in the management of diabetic macular edema. Am J Ophthalmol 2004;137:67582.

6. Pradeepa R, Anitha B, Mohan V, Ganesan A, Rema M: Risk factors for diabetic retinopathy in a South Indian Type 2 Diabetic population-The Chennai Urban Rural Epideiology Study4. Diabet Med 2008 May, 25(5):536-42.

7. Dayanand CD, Krishna Murthy $\mathrm{N}$, et al. Evaluation of Biochemical parameters evincing atherogenic potency in Type 2 Diabetic Retinopathy. Int J Biol MedRes 2011;2(2):539-542.

8. Aiello LP, Avery RL, Arrigg PG, Keyt BA, Jampel HD, Shah ST, et al. Vascular endothelial growth factor in ocular fluid of patients with diabetic retinopathy and other retinal disorders.

N Engl J Med 1994;331:1480-7.

9. Chew EY, Klein ML, Ferris FL 3rd, Remaley NA, Murphy $\mathrm{RP}$, Chantry K, et al. Association of elevated serum lipid levels with retinal hard exudate in diabetic retinopathy. Early Treatment Diabetic Retinopathy Study (ETDRS) Report 22. Arch Ophthalmol 1996 Sep;114:1079-84.
10. N Sachdev, Sahini A et al. Association of systemic risk factors with the severity of retinal hard exudates in a North Indian population with type 2 diabetes. Journal of Post Graduate Medicine 2010;56:3-6.

11. Anjana RM, Ali MK, Pradeepa R, Deepa M, Datta M, Unnikrishnan, et al. The need for obtaining accurate nationwide estimates of diabetes prevalence in IndiaRationale for a national study on diabetes. Indian J Med Res 2011 April;133(4):369-380.

12. Subhan SS, Rahman, Sayeed A, Hasin F, Karim R, Alif L. The Role of Duration of Diabetes in the Development of Diabetic Retinopathy in Young Diabetic patients in Bangladesh. J Bangladesh Coll Phys Surg 2009;27:133-138.

13. Raman R, Rani PK, Rachepalle SR, Gnaanamurthy P, Uthra S, Govindasamy K, Sharma T. Prevalence of Diabetic Retinopathy in India: Sankara Nethralaya Diabetic Retinopathy Epidemiology and Molecular Genetics Study Report 2. Ophthalmology 2009;116(2):311-318.

14. Dandona R, Dandona L, Naduvilath TJ, McCarty A, Rao GN. Population based assessment of diabetic retinopathy in an urban population in Southern India. Br J Ophthalmol 1999;83:937-940.

15. Lill-Inger Larsson, Albert Alm, Folke Lithner, Gosta Dahlen, Reinhold Bergstrom. The association of hyperlipidemia with retinopathy in diabetic patients aged 15-50 years in the county of Umea. Acta Ophthalmol Scand 1999;77:585-591.

16. Chew EY, Klein ML, Ferris FL. Association of elevated serum lipid levels with retinal hard exudates in diabetic retinopathy: Early Treatment Diabetic Retinopathy Study (ETDRS) Report 22. Arch Ophthalmol 1996;114:1079-84.

17. Ong Ming Jew, Mohammadrezah Peyman, et al. Risk Factors for Clinically Significant Macular Edema in a multi-ethnics population with type 2 diabetes. Int J Opthalmol 2012;5(4):499-504.

18. Singh R, Abhiramamurthy V, Gupta V, Gupta A, Bhansali A. Effect of Multifactorial Intervention on Diabetic Macular Edema. Diabetes Care 2006;29:463-4.

19. Dhananjay Shukla, et al.; Diabetic Retinopathy in Asia. Cataract \& Refractive Surgery Today. 64-68, Oct 2005.

20. Lill-Inger Larsson, Albert Alm, Folke Lithner, Gosta Dahlen, Reinhold Bergstrom. The association of hyperlipidemia with retinopathy in diabetic patients aged 15-50 years in the County of Umea. Acta Ophthalmol Scand 1999;77:585-591.

21. Rebab Benarous, Muhammed B Sasongko, et al. Differential Association of Serum Lipids with Diabetic Retinopathy and Diabetic Macular Edema. Invest Ophthalmol Vis Sci 2011;52:7464-7469. 